\title{
Livre iniciativa: Síntese filosófica, econômica e jurídica ${ }^{1}$
}

\author{
Free enterprise: Synthesis philosophical, economic and legal
}

\section{Adyr Garcia Ferreira Netto ${ }^{2}$ \\ Marlene Kempfer Bassoli ${ }^{3}$}

\begin{abstract}
Resumo
0 presente artigo pretende discorrer sobre o tema da livre iniciativa desde a sua fundamentação lógica filosófica, seus aspectos conceituais econômicos à sua positivação pela dogmática jurídica. Para tanto, inicialmente busca na distinção entre causalidade e imputação o ponto fundamental entre o mundo da necessidade e da liberdade. Perpassa pelos conceitos econômicos para compreensão de seus efeitos e, finalmente, apresenta o instrumental oferecido pela dogmática jurídica para dirimir e viabilizar a melhor forma de sua efetivação.
\end{abstract}

Palavras Chave: Livre iniciativa, imputabilidade, dogmática jurídica.

\begin{abstract}
This article aims to discuss the issue of free initiative from its logical philosophical basis, its conceptual economic aspects and legal dogmatics. Thus, initially looking at the distinction between causal attribution and imputability, the key point between the world of necessity and freedom. Permeates the economic concepts to understand their effects, and finally presents the instruments offered by legal dogmatic to settle and make the best of its effectiveness.
\end{abstract}

Keywords: Free initiative, imputability, legal dogmatics.

\section{Introdução}

Tema que encontra nas páginas econômicas a forma mais expressiva de sua identidade, a livre iniciativa permite por sua natureza policêntrica e multifacetada, uma

\footnotetext{
${ }^{1}$ Artigo construído a partir dos estudos do projeto de pesquisa "Estado e Relações Empresarias: Diálogos Filosóficos e Jurídicos diante da Regulação Estatal sobre a Ordem Econômica Nacional", realizado na Universidade Estadual de Londrina-Pr., vinculado ao Curso de M estrado em Direito Negocial e Departamento de Direito Público.

${ }^{2}$ M estre em direito negocial, especialista em filosofia política e jurídica UEL, graduado em economia, direito e filosofia. Professor da graduação na UNOPAR campus Londrina e Arapongas e professor da especialização de filosofia UEL. (introdução, fundamentação filosófica e aspectos econômicos).

${ }^{3}$ Doutora e mestra pela PUC/SP em Direito do Estado, professora da graduação, especialização e mestrado na UEL, UNIMAR-SP e PUC-PR campus Londrina. (positivação jurídica).
}

Revista de DiReito Púbuico, LondRINA, V. 4, N. 1, P. 155-172, JAN/ABR. 2009. 
abordagem interdisciplinar que transcende os lindes conceituais de seu rotineiro uso de perspectiva dogmática e unidimensional.

Tendo como precípuo escopo percorrer com passos largos o amplo horizonte que o tema se estende, este artigo inicia-se por um exame zetético de sua fonte filosófica, transitando pelos aspectos conceituais econômicos à positivação pela dogmática jurídica.

Por este tríplice diapasão, examinando desde sua gênese abstrata à sua validação legal, aspira-se, complementarmente, construir ferramental teórico suficiente para legitimar o incentivo e a práxis da livre iniciativa, concluindo por inexorável lógica, a dependência de sua instrumentalidade para alcançar progresso e desenvolvimento social.

\section{Fundamentação filosófica}

0 primeiro passo que conduz o homem ${ }^{4}$ à liberdade é o auto-reconhecimento de sua racionalidade ${ }^{5}$.

A implicação lógica do axioma resgata a distinção já traçada por Hans Kelsen (2002, p. 102) na Teoria pura do direito, entre a relação causal e o nexo de imputabilidade como demarcador entre as determinações necessárias da natureza e o plano da contingência e liberdade das ações humanas. Por esta perspectiva pretende-se fundamentar a necessidade lógica de compreender a livre iniciativa como parte inerente à condição humana ${ }^{6}$ antes de ser um conceito econômico ou de mera previsão normativa.

As conexões inflexíveis que unem as relações entre causa e efeito dos fenômenos da natureza engendram o logos que a mantém em intrínseca harmonia, proporcionando

\footnotetext{
${ }^{4} 0$ indivíduo reconhecendo sua condição racional infere, naturalmente, que toda humanidade é por extensão, racional e livre, e, a liberdade subsiste no mútuo respeito deste reconhecimento. A livre iniciativa é elemento do domínio da liberdade, guardando com ela reciprocidade e consistência conceitual. Como se demonstrará, basta ser racional para ter livre iniciativa. Por este prisma, é interessante notar que as crianças por não terem seu total potencial intelectual desenvolvido, não são livres, e por não dominarem sua razão, não podem ter por completo uma livre iniciativa ou uma ação autônoma e deliberada, são assim inimputáveis, não se responsabilizando por ações morais ou imorais.

${ }^{5} 0$ referencial lógico deste artigo não permite o pressuposto de uma existência da liberdade ou da moralidade como dado objetivo, pois liberdade é expressão meramente conceitual e abstrata, desprovida de qual quer sentido ou correspondência com o concreto. É importante ressaltar que a implicação desta preleção leva em consideração a perspectiva lógica de que, por pacto conceitual, o que é livre não é preso, o que é livre não está condicionado (a não ser pela própria deliberação racional), ou ainda, as ações livres são frutos da racionalidade, e não pela sua existência autônoma. Vide nota $n . \underline{0} 9$.

6 "Condição humana" não está amparada por um pressuposto metafísico da existência de uma natureza humana, mas de suas qualidades implícitas. Insista-se que a linha que se segue considera qualquer elemento metafísico desprovido de sentido, as inferências lógicas dizem respeito, como se disse na nota anterior, a uma relação conceitual.
} 
pelo controle dos resultados, expectativa revestida de objetividade, necessidade e universalidade.

Inspirado no liame conectivo entre o antecedente (causa) e o conseqüente (efeito) dos elementos factuais que dinamizam este desdobramento linear racionalmente previsível, as doutrinas do direito encontram no princípio da imputação a possibilidade de atribuir responsabilidade moral e jurídica como contrapartida de uma deliberação racional e volitiva do agente ao praticar condutas cuja previsibilidade legal é estabelecida em hipótese de incidência de uma prescrição normativa.

[...] vale a pena insistir no fato positivo de kelsen ter-se inspirado em Kant para aceitar a distorção entre o "mundo da natureza", ou Sein, e mundo da cultura, Sollen. 0 neokantismo de Kelsen atenuava, desse modo, a sua aversão a toda colocação axiológica da problemática científica. Isto levou-o distinguir com grande acuidade entre causalidade e imputabilidade. Reale (1984, p.27)

Nas determinações da natureza não há liberdade nem deliberação volitiva, a conexão causal ocorre independente de qualquer força ou vontade autônoma. No plano da liberdade, onde ocorrem as relações humanas, as condutas individuais encontram na autonomia da razão a motivação de seus atos, e a situação de fato que ocupa 0 antecedente causal refletirá como efeito as convicções morais que residem no interior de toda subjetividade, por esta razão, a possibilidade sancionadora personalíssima daquele condicionante legitimado por aspecto rigorosamente idiossincrático. É o que parece ser sustentado na Teoria pura do direito ${ }^{7}$.

No fundo, o que Kelsen quer dizer é que, enquanto as relações entre os fatos naturais são explicados segundo o conceito de causalidade, as relações entre as atividades humanas, nos planos ético e jurídico, se compreendem segundo a idéia de imputação. Reale (1984, p.27)

Não se pode imputar responsabilidade moral às ações instintivas ou ações cuja deliberação racional não permitiria conduta divergente. A responsabilidade moral medra da faculdade da razão e da possibilidade de conduta diversa ${ }^{8}$. Um ser desprovido de razão que

\footnotetext{
${ }^{7}$ Não há necessariamente um apego teórico deste artigo ao normativismo kelseniano. A referência é feita pela natureza discursiva brotar da distinção entre causalidade e imputação, comum aqui e na Teoria pura do direito.

${ }^{8}$ A previsão legal de excludentes de ilicitudes fundamenta-se na impossibilidade de conduta diversa, ou seja,
} 
aja por mero impulso instintivo não pode agir moralmente e, por conseqüência, não pode ser responsabilizado por suas ações justamente por não ter liberdade. Neste caso não haveria o liame de imputação conectando prescrição hipotética incidental com a respectiva responsabilidade, nem sentido ou expectativa de modificação de comportamento imposta em funtor normativo.

Não se pode atribuir aos animais, por exemplo, condutas morais, pois não há faculdade racional desenvolvida a ponto de optar por deliberação da vontade uma ação conforme um dever legal ou moral. Momentaneamente, pode-se supor que por estes motivos não se poderia atribuir deveres nem direitos subjetivos ${ }^{9}$ a eles.

Os homens, seres dotados de razão, podem diante de uma situação de fato optar livremente por assumir determinadas posturas, que após avaliar as conseqüências, se responsabiliza, ou é sujeito a responsabilidades, por agir de acordo ou não com as proposições prescritivas do direito.

Precisamente nesta condição racional é que reside a natureza livre do indivíduo. 0 homem é livre porque pensa, porque vivendo no incerto e imprevisto mundo das contingências, pode escolher e decidir a postura a ser adotada diante de um fato ou relação intersubjetiva. Fosse hipoteticamente despojado ou privado do homem suas volições e compleições, e este passasse a agir de forma singular, instintiva ou reflexa no complexo domínio da intersubjetividade, a subsunção fática normativa não encontraria respaldo ou responsabilidade psicológica personalíssima para o antecedente causal, ainda que prevista em hipótese de incidência, nem atribuição legitima para implicação deontológica de conseqüente prescritivo legal ou moral, pois a motivação de seu comportamento transcenderia ao controle subjetivo.

não se pode penalizar alguém por agir da única forma possível.

${ }^{9}$ É necessário ressaltar que o raciocínio inspira-se no mesmo fundamento defendido por Kelsen quando reduz o direito a norma. Sem prejuízo do prisma zetético, é possível considerar elementos ditos metajurídicos pelo juspositivismo, como pressupostos lógicos, ainda que não necessariamentes jurídicos. Não há questionamento em relação à idéia de estar na validação da norma o elemento jurígeno, que considera o direito subjetivo mero reflexo do direito objetivo, ou seja, conceito técnico do direito que não implica na sua existência ontológica. 0 raciocínio proposto, em hipótese alguma considera o direito da livre iniciativa como uma questão ontológica, mas apenas lógico e conceitual. Desta forma, é possível considerar a livre iniciativa como qualidade naturalmente humana pela implicação da racionalidade, não como um direito subjetivo independente da norma objetiva ou existente no plano ontológico. 0 direito subjetivo das crianças, por exemplo, não está condicionado pela razão, pois como se disse, esta ainda não está desenvolvida suficiente para perceber que é livre, mas por reflexo de uma norma objetiva. Pela percepção zetética, segue-se 0 entendimento neopositivista e analítico onde todos os "problemas metafísicos" são desprovidos de qual quer sentido. 
Sublata causa, tollitur effectus ${ }^{10}$. Eis o núcleo nevrálgico da liberdade, das determinações necessárias, e da imputação deontológica!

Se existem condicionantes no âmbito social ou educacional como causa e motivação das deliberações racionais ${ }^{11}$, é hipótese cuja profundidade não se pretende atingir neste artigo. Toma-se como ponto de partida a razão como referência e causa da livre expressão de um comportamento. A desconsideração desta premissa aventaria possibilidade de desconexão jurídica imputativa, atribuída ao fato das ações serem meras variáveis de um condicionante paradigmático metaindividual.

Ante este argumento Hans Kelsen levanta sutil observação: "A imputação não pressupõe nem o fato nem a ficção da liberdade como indeterminação causal, nem o erro subjetivo dos homens que se crêem livres. [...] Com efeito, a consciência de se poder agir como se quer é a consciência de que nossa ação é causada pela nossa vontade". Kelsen (p.107, 2002). Ressalte-se que esta advertência orbita em torno da imputação ético-jurídica como núcleo e referência da responsabilidade moral, ou a vontade como causa do efeito conduta.

\begin{abstract}
M uito freqüente é 0 asserto de que é necessário admitir que o homem tem uma vontade livre, isto é, não determinada casualmente, para explicar por que é que apenas consideramos ético-juridicamente responsável o homem e não as coisas inanimadas, os fenômenos da natureza ou os animais - para explicar por que é que apenas consideramos imputável 0 homem. Mas 0 certo é que apenas consideramos imputáveis os homens porque e na medida em que as ordens morais e jurídicas apenas prescrevem condutas humanas. [...] A explicação não está, portanto, na liberdade mas, inversamente, na determinação causal da vontade humana. Kelsen (2002, p. 107-108)
\end{abstract}

Novamente é necessário destacar que este posicionamento diz respeito a possibilidade de imputação de uma sanção (conseqüente) a vontade (causa), e por este diapasão haveria causalidade suficiente para responsabilidade jurídica ${ }^{12}$.

A fundamentação lógica filosófica de um princípio de liberdade cujo domínio está implícito a livre iniciativa não se confunde com a deontologia dogmática ou a necessidade de

\footnotetext{
${ }^{10}$ Suprimida a causa desaparece 0 efeito.

${ }^{11}$ Hipótese de reducionismo dos juízos morais aos juízos de fato.

${ }^{12}$ É possível pressupor pelo prisma normativista, que os animais não são possuidores de direitos subjetivos nem de responsabilidade moral por ausência da faculdade deliberativa, mas por falta de previsibilidade legal. A propósito, seguindo a linha normativista, justifica -se pelo conteúdo não ser jurídico, mas metajurídico. A liberdade do homem é um problema filosófico e não jurídico.
} 
imputabilidade jurídica, pois estas pressupõem que a conduta não seja autônoma em relação à vontade e aquele é implicação lógica da própria condição racional. A livre iniciativa não se justifica pelo ordenamento jurídico, sua gênese não se encontra nas leis escritas, mas na própria racionalidade. Antes de um dever ser, a livre iniciativa é uma imposição lógica gerada pela condição humana.

Segundo os filósofos, a liberdade é a consciência que temos de nossas possibilidades de escolha; ela é poder de decisão, mas não envolve o poder de execução.

Ela é sempre interior, subjetiva. Louis Baudin (1978, p.56)

Não se pode por esta perspectiva reduzir os juízos morais às relações de causalidade. As ações humanas são, por natureza, fruto de deliberação do espírito livre e racional inerente ao sujeito ${ }^{13}$.

Ante estas considerações, conclui-se que, conceitualmente, a liberdade subsiste na capacidade racional do homem, ou seja, a liberdade é inerente ao humano e, por conseqüência, a livre iniciativa justifica-se antes dos seus benefícios econômicos, ou pela própria positivação jurídica, pela faculdade deliberativa do indivíduo. Em outras palavras, a livre iniciativa antes de um direito, é implícita e necessária pela condição lógica do pressuposto da racionalidade e da liberdade.

\section{Aspectos econômicos}

Condicionada a deliberação individualizada, a livre iniciativa é conceitualmente autônoma à sociedade, e no âmbito econômico, se impõe como necessária ao seu desenvolvimento. Por adequação do princípio omnivalente da identidade lógica, a esfera mercadológica segue o pensamento de que ser livre é não estar condicionado por elementos heterônomos, implicando na forma livre do mercado, ou na livre concorrência.

\footnotetext{
${ }^{13}$ No plano político, hipótese contrária por vezes é sustentada com interesse de condicionar os homens a agir de forma reiterada e programada a comandos pré-estabelecidos, acortinada pelo populismo, legitima 0 totalitarismo e os Estados ditatoriais. Algumas ideologias econômicas propõem o fim da livre iniciativa, cabendo ao Estado decidir qual forma de reprodução material que cada um deve ter em função de um "interesse popular", ou ainda qual profissão o indivíduo exercerá. Nesta esteira, muitos Estados concentraram poder de tal forma, que a propriedade do indivíduo passar ser do Estado, a opinião do indivíduo passa a ser do Estado, as ações do indivíduo são a partir do Estado, o próprio pensamento e expressão do indivíduo passam a ser o pensamento e a expressão do Estado. Ceifar a liberdade do homem é aprisionar seu espírito, é manipulá-lo, é retirar-Ihe a faculdade de pensar.
} 
Vale ressaltar que o reconhecimento da condição deliberativa individualizada leva inexoravelmente a inferência extensiva de que todos são racionais e livres, e, o mútuo respeito deste pressuposto implica na expressão e manutenção da própria liberdade, válida também nas relações comerciais. Nestes termos, só há liberdade se os sujeitos se reconhecerem livres, e o conjunto de proposições normativas estariam, por implicação lógica, legitimadas a tutelar e afirmar a liberdade por forma interventiva.

Conforme citação acima de Louis Baudin, "a liberdade não envolve o poder de execução", portanto, a necessidade de intervenção jurídica (Estado), na realização e afirmação da liberdade no âmbito econômico.

0 aparente paradoxo exsurgente, entre a intervenção jurídica e a esfera da liberdade econômica, sutilmente desvanece-se quando a prerrogativa de modificar comportamentos das proposições prescritivas pretende restabelecer conduta negatória a intrínseca relação de liberdade engendrada no próprio meio de reprodução material dos sujeitos. Estabelecer como ilícito, ou imputar sanção àquilo que nega a liberdade é a pura expressão do que é livre, negar a negação da liberdade é afirmar a própria liberdade.

A conduta humana no âmbito das relações comerciais movidas tão somente pela racionalidade instrumental plutocrática, afronta a lógica extensiva da liberdade e da livre iniciativa, legitimando, deste modo, a ação do Estado sobre ${ }^{14} 0$ domínio econômico pela proteção e afirmação da liberdade, e por conseqüência, da livre iniciativa ${ }^{15}$. Liberdade não se confunde com licenciosidade, é o que se demonstrará pelos instrumentos constitucionais no tópico sobre a positivação jurídica.

Ainda alinhado ao pensamento de Louis Baudin (1978, p.56), a palavra liberdade serviu de brado de união a muitos revolucionários, mas há tempo seu sentido tem sido deformado e obscurecido. No domínio econômico, para o antigo professor da universidade de Paris, a liberdade se reveste da forma passiva e ativa. A primeira consiste na ausência de coação (liberdade de indiferença); a segunda supõe comportamento autônomo do indivíduo (liberdade de compromisso), e as duas, formam um círculo simbiôntico de mútua dependência. Ao se abrirem as portas de uma cadeia, propõe Baudin (1978, p. 57), o preso

${ }^{14} 0$ termo "sobre" o domínio econômico distingue-se do termo "no" domínio econômico. O primeiro diz respeito ao Estado como fonte normativa, regulador, no segundo, como agente participativo.

${ }^{15}$ No tópico sobre a positivação jurídica se desenvolverá os mecanismos judiciais legítimos para preservação e afirmação da livre iniciativa, tendo como referência, a Constituição da República Federativa do Brasil. 
pode por hábito ser incapaz de assumir uma escolha, e seja qual ela for, torna-se uma liberdade ativa. "Não julguemos o homem sempre desejoso de ser livre, pois ele pode estar cansado da liberdade, ou mesmo considerar-se como um condenado à liberdade"

Assim, os povos que foram por longo tempo dirigidos conservam às vezes o gosto dessa coação e temem ser delas privados: os índios dos Andes, sujeitos a um regime socialista minucioso e previdente, temem a liberdade que os forçará a decidir e a agir por si mesmos. Do mesmo

modo, em grau menor, numerosos indivíduos alienam a própria liberdade de expressão e ação, enfeudando-se a um agrupamento tirânico do qual esperam vantagens materiais. A obediência é uma solução fácil para os medíocres. Louis Baudin (1978, p. 57)

Esta visão liberal pressupõe como exposto, que o indivíduo não tem o espírito de escravo, o que para muitos, pode ser postura difícil a ser adotada.

A livre iniciativa na economia é uma liberdade ativa, pois a forma de reprodução material da vida, por esta perspectiva, é dependente do indivíduo, da sua força de vontade e dedicação.

A liberdade ativa é temida, porque tem por consectários certos companheiros muito desacreditados hoje em dia: o risco e a responsabilidade. No domínio econômico, o produtor livre pode enganar-se, porque o cálculo econômico é difícil, o futuro é incerto, as perturbações sociais ou os caprichos da moda podem transformar as previsões. Fracassando, ele só pode culpar a si próprio. Aí está a sua grandeza e a justificação de seu lucro: ele desempenha o papel de pioneiro, de explorador; numa palavra, ele é o chefe. Louis Baudin $(1978$, p.60)

Seguindo a preciosa lição,

0 medo do risco e a fuga das responsabilidades atestam uma mediocridade de caráter que anuncia o declínio da nação. 0 indivíduo torna -se incapaz de suportar as "pressões emocionais" engendradas pelas incertezas, pelas mudanças, pelas inovações provocadas por um progresso realizado em ritmo acelerado. A sociedade liberal vibrante, na qual formas novas estão sempre em gestação, ignora as necessidades da calma, de rotina, de segurança. Louis Baudin, (1978, p.60)

Contudo, é preciso de condições para efetivar a liberdade na economia, para tanto, justifica-se, como já esclarecido, a intervenção jurídica na ordem econômica com proposição de garantir a liberdade extensiva. Isto não significa estabelecer limites à liberdade, tampouco permitir uma "liberdade parcial" dos agentes econômicos, cuja expressão por si é contraditória, mas intervir para negar através das normas, o que nega a liberdade. “[...] a 
liberdade é una, de onde resulta que as liberdades estão vinculadas entre si, que elas são solidárias. Quando uma delas é destruída, as demais estão ameaçadas, Se a imprensa é condenada a obedecer, a palavra o será em breve" ${ }^{16}$._Louis Baudin $(1978$, p. 65)

O sentido técnico econômico da livre iniciativa mantém a idéia de opção autônoma de escolha, de deliberação racional individual.

Pela visão enciclopédica do verbete "livre iniciativa", de acordo com Paulo Sandroni, pode ser assim interpretada:

Princípio do liberalismo econômico que defende a total liberdade do indivíduo para escolher e orientar sua ação econômica, independente da ação de grupos sociais ou do Estado. A liberdade para as iniciativas econômicas, nesse sentido, implica a total garantia da propriedade privada, o direito de o empresário investir seu capital no ramo que considerar mais favorável e fabricar e distribuir os bens produzidos em sua empresa da forma que achar mais conveniente à realização dos lucros. Os limites da livre-iniciativa, de acordo com a economia clássica, estariam determinados no próprio sistema de concorrência entre empresários particulares, cabendo ao Estado apenas garantir a manutenção dos mecanismos naturais da economia de mercado. Das condições atuais do desenvolvimento capitalista, a necessidade de defender o sistema dos efeitos das crises cíclicas levou o Estado a impor limites a livre-iniciativa seja atuando diretamente no processo produtivo, seja agindo como elemento orientador de investimentos e controlador de desajustes sociais. Paulo Sandroni (1999, p.352)

A livre iniciativa manifesta-se na economia pelo mercado livre e, portanto, da livre concorrência (ou concorrência perfeita).

Ainda que seja uma estrutura de mercado hipotética, fictícia, pois sempre haverá distorções do seu real funcionamento, tal qual uma sociedade livre e justa é pretendida pelo direito, a livre concorrência é referência para toda economia democrática, não dirigida ou condicionada por ideologias políticas, econômicas ou totalitárias. A “ideologia da livre concorrência" e da livre iniciativa, não é propriamente uma ideologia na medida em que busca a afirmação da liberdade, como já comentada, conceitualmente condição do próprio humano.

Conforme José Paschoal Rossetti (1997, p.401), este modelo de estrutura de mercado é caracterizada basicamente por:

Atomização: Pelo grande número de concorrentes atuando no mercado, nenhum deles teria força suficiente para influenciar sozinho no preço de equilíbrio.

\footnotetext{
${ }^{16}$ Grifo nosso.
} 
Homogeneidade: Não há diferenciação entre os produtos e serviços, ou seja, o produto que um agente oferece, é um substituto perfeito de outro concorrente. Se houver diferença entre os produtos ofertados, não se pode afirmar que existe equilíbrio concorrencial entre eles. Por exemplo: Um carro popular compete com outro carro popular, mas não com um carro de luxo, este não faz parte do mesmo mercado de preços.

Mobilidade: Não há restrições artificiais como intervenção do governo; as empresas podem entrar e sair do negócio sem qualquer impedimento; há independência entre os concorrentes, ou seja, um não impõe restrição às modificações ou decisões de outros.

Permeabilidade: Não existem restrições ou barreiras para entrada e saída de agentes no mercado. Se o mercado de um determinado produto exige investimentos de grande ordem financeira, isto é um impedimento e, descaracteriza a concorrência ideal.

Preço-limite: 0 preço é dado pelo mercado, assim, nenhum dos agentes compradores ou vendedores podem isoladamente influenciá-lo.

Extra-preço: Não pode haver nenhum tipo de compensação como vantagens adicionais associadas ao produto, pois descaracterizaria o padrão entre concorrentes.

Transparência: Ninguém detém informações privilegiadas que possam modificar o mercado. 0 acesso de novos investidores neste mercado não pode ser dificultado por posse exclusiva de informação daqueles agentes já ofertantes.

É de suma importância a compreensão de que mercados monopolísticos ou oligopolísticos podem, dependendo do produto e das circunstâncias (ofertante de um produto exclusivo, por exemplo), serem perfeitamente aceitos. A propósito, o mercado regido por monopólios não é ilegal, mas o uso deste poder econômico para criar barreiras à entrada de novos concorrentes deve ser vigorosamente combatido pelo direito.

Como não se bastasse a conclusão lógica e filosófica de que a livre iniciativa é naturalmente humana, estudos comprovaram ${ }^{17}$ que nos últimos 50 anos houve uma relação inexorável entre a liberdade econômica e a eliminação da pobreza, a promoção do desenvolvimento humano, o crescimento econômico, a proteção do meio ambiente, promoção de valores sociais positivos como a democracia, dignidade, combate à coerção de

\footnotetext{
${ }^{17}$ Acesso em 30 mar. 2009. http://www.heritage.org/Index/PDF/Index09_Chapter2.pdf
} 
regimes totalitários, liberdade de expressão, entre outros ${ }^{18}$. A promoção da liberdade possui legitimidade lógica, filosófica e econômica!

Para sua legitimidade legal, serão agora tratados os instrumentos constitucionais positivados pela ordem jurídica brasileira.

\title{
Positivação jurídica
}

A fonte material do Direito são as relações humanas nos seus mais diversos domínios. Para Vilanova (2003, p.367), ao tratar sobre a Política e o Direito, refere-se a experiência humana que ocorre na realidade social e que pode ser apontada como fonte acima referida:

\begin{abstract}
A realidade social que nos é dada na experiência é uma multiplicidade interrelacionada. Não é o conjunto de um só facto, nem uma pluralidade dispersa de factos. Nem tampouco esses factos múltiplos se dispões, linearmente, como em série, sempre uniformes em sua composição interior. Dispõem-se em segmentos, uns subpostos, outros sobrepostos, uns em coordenação, outros em relação de subordinação, de tal sorte que a realidade social apresenta-se como uma heterogeneidade estruturada.
\end{abstract}

O Direito por meio de seu instrumento normativo pretende apreender aspectos relevantes desta complexa realidade para conduzí-la conforme a racionalidade do dever ser. Assim o faz através do processo legislativo inaugural19, percorrendo os primeiros momentos da positivação, onde é possível constatar a idéia da imputação deôntica já referida.

Neste processo há a seleção de fatos sociais, econômicos, financeiros, familiares e de outros domínios, que passam a ter relevância jurídica ao compor a estrutura de uma norma jurídica de direito material. A este antecedente normativo se vincula, por uma relação de implicação lógica, a relação jurídica entre sujeitos de direito cujo vínculo tem por objeto condutas prescritivas proibidas, permitidas ou obrigatórias. Tais modais deônticos têm a finalidade de impor aos sujeitos a realização, no plano da intersubjetividade ou da realidade social, os valores jurídicos elevados a esta condição por este mesmo processo.

Conduzir as condutas humanas por meio do dever ser é a interferência jurídica na

\footnotetext{
${ }^{18}$ Na publicação do "2009 index of economic freedom" (índice de liberdade econômica) da Heritage Fundation, o Brasil ocupa 105. lugar. Acesso em 30 mar. 2009. http:// www.heritage.org/Index/Ranking.aspx
} 
liberdade humana. Para a garantia do cumprimento dos deveres jurídicos deve haver mais uma norma jurídica, a de direito processual, em cuja estrutura tem-se a previsão da antijuridicidade e, novamente, a este antecedente, por meio da relação de implicação lógica, está vinculada a sanção. Este processo de positivação tem como fonte primeira os valores jurídicos, avança para a construção de normas abstratas e gerais (lei) e se conclui com a produção das normas concretas e individuais (sentenças, acórdão, atos administrativos).

Radbruch $(1999$, p.37) aponta a lei como marco que baniu quase totalmente 0 direito consuetudinário e também indica o Estado "como fonte de praticamente todo o direito." Anota que o Estado além de fonte é produto do direito sendo sua existência jurídica a partir da Constituição, nascedouro de todo o ordenamento jurídico e, indiscutivelmente, do Direito Público.

É a partir do nível da Constituição que é possível verificar toda a hierarquia normativa do estado. Esta análise formal da positivação se complementa com análise do conteúdo normativo do ordenamento. Cada nação em determinado momento e espaço decide sobre quais relações humanas o estado, por meio das normas jurídicas, poderá intervir.

0 fato é que 0 texto constitucional é referência obrigatória para identificar os valores jurídicos do ordenamento, as estruturas da organização político-administrativa do estado, o poder político (governo) e a forma de seu exercício. Estes são conteúdos constitucioinais necessários. Outros podem estar neste nível jurídico, mas, isto depende de decisão política registrada por ocasião da aprovação do texto constitucional por uma assembléia nacional constituinte.

Sendo assim e dirigindo-se a partir desta etapa deste estudo à Constituição da República Federativa do Brasil que inaugurou o atual Estado (05/10/88), é possível descrever tanto 0 aspecto formal quanto material do percurso da positivação do tema da livre iniciativa em direção ao domínio econômico.

Para tanto é preciso indicar que a partir do preâmbulo da Constituição/88 tem-se indicação da liberdade como valor jurídico: Nós, representantes do povo brasileiro, reunidos em Assembléias Nacional Constituinte para instituir um Estado Democrático de Direito, destinado a assegurar o exercício dos direitos sociais e individuais, a liberdade.... .

0 valor jurídico da liberdade se positiva mais adiante no texto constitucional como 
fundamento da República Federativa do Brasil na forma da livre iniciativa (Art. 1으, IV da CF/88). É a primeira manifestação com caráter normativo autorizando (modal da permissão no sentido de competência jurídica) a intervenção do Estado brasileiro, por meio dos governos, sobre o domínio econômico, para garantir a vivência com o valor liberdade na forma da liberdade econômica. Observe-se que, conforme ensinamentos de Vilanova (2003, 375) o quantum de politicidade nas relações econômicas é uma opção democrática, destacando que:

Não é a Economia que confere a normatividade, é a normatividade que traça a diretriz da ação social econômica, como lhe dá o sustentáculo da eficacidade. Mesmo no apoliticismo da economia liberal - o máximo de sociedade e o mínimo de Estado - temos uma tomada de posição valorativa e normativa, constitucionalmente garantida.

A partir destas considerações segue-se a análise jurídica da livre iniciativa no título que dispõe sobre os Direitos e Garantias Fundamentais, indicando o texto constitucional que a livre iniciativa é um direito desta envergadura. Tal conclusão é possível a partir do que está explicitado no Art. 5ํ, XIII no sentido de que esta liberdade ativa é direito ao exercíco de qualquer trabalho, ofício ou profissão; da mesma maneira ao tratar do direito à propriedade em que está implícito que o seu titular poderá livremente usar, gozar e dela dispor, também, para seus empreendimentos econômicos (Art. 5ํ, XXII).

Optando por reservar um capítulo da Constituição/88 para dispor sobre o regime jurídico-econômico constituciconal, onde estão os princípios gerais da atividade econômica, o legislador constituinte repete no caput do Art. 170 que a ordem econômica, deve fundarse na valorização do trabalho humano, no valor dignidade, no valor da justiça social e na livre iniciativa.

0 exercício desta liberdade, portanto, é direito fundamental e deve ser considerado pelos hermenêutas como integrante dos direitos a serem vivênciados em um Estado Democrático de Direito, paradigma contemporâneo para as interpretações jurídicas em direção à efetividade do ordenamento diante da vida.

Conforme já exposto quando se tratou da livre iniciativa no aspecto econômico este direito fundamental manifesta-se na economia de mercado livre, ou seja, onde as possiblidades positivas da livre concorrência se manifestam. A livre iniciativa e a livre 
concorrência são direitos que caminham lado-a-lado, portanto, tutelar a livre iniciativa é tutelar a livre concorrência e vice-versa. Santiago (2008, p.44) ao tratar da livre concorrência na constituição destaca o voto da conselheira do CADE Lucia Helena Salgado no exame do ato de concentração no 83/96:

[...] a livre concorrência constitui 'um valor, um bem, da perspectiva pública da sociedade, e não da perspectiva privada. Por isso, a necessidade de uma política de Estado de promoção de defesa da concorrência. Essa política de Estado está longe de ser confundida com políticas de governo, que, quase sempre, buscam resultados de curto prazo', e que, muitas vezes, sacrificam a livre concorrência para atender a interesses e fins privados.

Mais uma vez destaca-se a necessidade da intervenção estatal por meio de seus órgãos para possibilitar normativamente o exercício destes direitos. Desta forma estar-se-á viabilizando um mercado interno saudável e o Estado cumprindo com seu dever constitucional de preservá-lo uma vez que foi elevado à condição jurídica de patrimonio nacional (Art. 219 CF)

É certo que contemporaneamente tem-se que conviver com direitos fundamentais individuais, sociais e transindividuais, ou seja, com as dimensões de todas estas conquistas. Confirma Gomes (2008, p. 208) que a convivência em sociedade requer o convívio de múltiplas liberdades, ou seja:

Em sendo a liberdade um atributo indispensável à configuração do próprio modo de ser humano em sua plenitude, a convivência em sociedade requer o convívio das múltiplas liberdades. Para que isso seja possível, é necessário haver limites que possibilitem a todos e a cada um o exercício da liberdade de forma responsável.

Portanto, o Estado, cumprindo com as atribuições que Ihe foram reservadas poderá intervir sobre domínio econômico para possiblitar tal convivência delimitando e hierarquizando direitos. Assim o faz por meio das funções de produzir normas inaugurais (Legislativo), de execução e fiscalização dos deveres trazidos por estas normas (Executivo) e resolver conflitos que podem surgir diante das complexas relaçoes econõmicas (Judiciário).

No domínio econômico tais limites poderão estar presente, ou seja, há autorização constitucional para a intervenção estatal em várias passagens do seu texto. Já a partir do Art. 5ํ, XIII e fica confirmada no parágrafo único do Art. 170, ao possibilitar que limitações sejam 
trazidas ao ordenamento por lei. Esta interferência legal na liberdade de iniciaitva somente se justifica se observadas limitações constitucionais, tais como: i) não mitigar o direito de acesso ao mercado em nível tal que desistimule esta liberdade ativa ou ao ponto de comprometer a livre concorrência; ii) desde que seja para possibilitar a convivência com outros direitos fundamentais de igual envergadura, em especial com os direitos transindividuais.

A intervenção no domínio econômico está autorizada conforme se pode concluir da interpretação do Art. 173, § 40 da CF/88 ao condenar o aumento arbitrário dos lucros, que poderá configurar condutas de abuso do poder econômico com consequências indesejáveis como a dominação dos mercados. Tal hipótese se concretizada reflete diretamente em dificuldades para vivenciar plenamente o direito à livre iniciativa e à livre concorrência.

Outra manifestação constitucional permissiva de intervenção em favor desta liberdade é quando autoriza tratamento diferenciado para as micoempresas e empresas de pequeno porte (Art. 170, IX CF/88). Quer-se possiblitar a vivência do valor liberdade com 0 valor igualdade em sua perspectiva material. Os governos podem tratar os agentes econômicos de modo diferente pelo critério discríminem da capacidade econômica e, por meio, por exemplo, de incentivos ( Art. $179 \mathrm{CF} / 88$ ) às iniciativas de pequenos empresários, viabilizar a livre iniciativa (acesso), bem como a possibilidade de permanecer na atividade econômica para fortalecer um mercado concorrencial.

Neste caminho dos incentivos há outra passagem constitucional no Art. 146-A, em que se verifica a autorização para os governos utilizarem-se de mecanismos tributário para prevenir desiquilibrios que possam afetar a concorrência, pois, certamente poderão ter reflexos na livre iniciativa.

Conforme se pode avaliar a positivação do valor liberdade como um valor jurídico econômico para se realizar no convívio humano das relações econômicas, percorre várias passagens constitucionais. É a partir das competências constitucionais que o caminho segue para a continuidade deste processo em nível legal. Com fundamento nesta permissão é que no Brasil tem-se um conjunto normativo de defesa da livre iniciativa e da concorrência, 0 Sistema Brasileiro de Defesa da Concorrência (SBDC). Nele se destaca a Lei 8884 de 11 de junho de 1994 e que no seu Art. 10 expressa quais as finalidades das normas que compõem 
este corpo legal:

Art. 10 Esta Lei dispõe sobre a prevenção e a repressão às infrações contra a ordem econômica, orientada pelos ditames constitucionais de liberdade de iniciativa, livre concorrência, função social da propriedade, defesa dos consumidores e repressão ao abuso do poder econômico.

A continuidade da positivação pode-se verificar com o poder regulatório em nível administrativo por meio de atos administrativos tanto do chefe do órgão executivo federal quanto da autarquia especial (agência reguladora) Conselho Administrativo de Defesa Econõmica (CADE). Nos termos da lei supra referida este órgão tem, inclusive, atribuição judicante, significa afirmar que pode produzir normas concretas e individuais e assim alcançar o nível das relações econômicas impondo a estes sujeitos as condutas consideradas legítimas pelo Direito. Este é o percurso da positivação: Constituição/88 $\rightarrow$ leis $\rightarrow$ atos administrativos ou sentenças/acórdãos $\rightarrow$ realidade social.

Sob o aspecto jurídico-econômico a positivação do valor liberdade $\rightarrow$ livre iniciativa $\rightarrow$ livre concorrência deve possiblitar a convivência com valores fundamentais e inerentes à atividade econômica: eficiencia produtiva e eficacia alocativa. Somente assim será possível que se realize a justiça nesta dupla perspectiva. Conforme Paschoal Rossetti (p.205, 1997), eficiência produiva e eficácia alocativa têm as seguintes dimensões:

Emprego eficiente de recursos produtivos. No limite, a busca do_pleno-emprego dos fatores de produção, como redução para zero de disfunções como 0 subemprego e o desemprego involuntários.

Máximo aproveitamento dos recursos empregados. Potencialidades e_capacidades ineficientes utilizadas implicam desperdícios socialmente injustificáveis.

Escolhas sobre 0 que e quando produzir. Compatíveis com as_aspirações da sociedade, quanto à sustentação do bem-estar corrente e à progressiva melhoria de níveis e padrões.

Desconsiderar estas questões é afrontar a racionalidade econômica o que, certamente, não contribuirá para a efetividade do Direito neste domínio.

\section{Conclusão}

Em seu aspecto filosófico, considerando o pacto conceitual onde a liberdade é possibilidade de opção de conduta motivada exclusivamente por deliberação individual, 
condicionada à razão, conclui-se a livre iniciativa como inerente ao humano, pois sendo elemento do domínio da liberdade, guardando com ela relação coerencial, não pode ser inibida ou ceifada sem prejuízo da contradição com sua própria natureza.

Sob o prisma econômico, seguindo a inferência filosófica, é imperativo que se preserve esta natural condição de liberdade como pressuposto de qualquer sistema de reprodução dos meios materiais, e o campo possível para efetivação desta autonomia é o mercado da livre concorrência. Considerando a incapacidade humana de auto-limitação, muitas vezes seduzida às ingerências da racionalidade plutocrática própria das relações comerciais, reconhece-se por legítima a intervenção do Estado sobre o domínio econômico para manutenção e promoção da liberdade, no sentido de garantir a todos a oportunidade da livre iniciativa, negando através do direito, aquilo que a nega.

0 direito fundamental à livre iniciativa é a possibilidade da vivência com 0 valor liberdade jurídica que se manifesta nas ações humanas no domínio econômico. 0 percurso da positivação deste valor, até realizar-se nas complexas relações econômicas, inicia-se no nível constitucional. A fonte do valor está no preâmbulo onde a liberdade é referida e compõe-se como valor jurídico. Segue para o campo econômico sob a forma de livre iniciativa e elevado a fundamento do Estado brasileiro no Art. 1o, IV CF/88. Segue para ser reconhecido como direito fundamental (Art. 50, XIII e XXII CF/88) e finalmente se aloja do regime jurídico-econômico constitucional (Art. 170 CF/88).

A livre iniciativa é a garantia de acesso ao mercado. Quando isto se realiza possibilita um mercado concorrencial que, entre outros benefícios, proporciona: aos agentes econômicos permanência no mercado; ofertas e preços de produtos e serviços para escolha do consumidor; qualidade resultante de investimentos em novas tecnologias; igualdade de oportunidades para o trabalho e emprego; desenvolvimento econômico. Por estas constatações é que o mercado nacional é considerado patrimônio nacional (Art.219) e nesta condição deve ser preservado pelo Estado, sociedade e agentes econômicos.

Com esta missão o Estado tem permissão constitucional (permissão como competência) de intervir para que direitos possam conviver, por exemplo: propriedade com propriedade e função social; liberdade da atividade econômica com preservação ambiental; livre concorrência com controle de atos de concentração. Esta intervenção se dá por meio de normas jurídicas com a finalidade de prescrever condutas e se inicia pelo exercício da 
competência prevista na Constituição, segue para o nível da lei e poderá se concluir com a produção de normas concretas individuais produzidas em processos administrativos ( atos administrativos) ou judiciais (sentenças e acórdãos).

Para a efetividade da ordem jurídica é preciso compatibilizar os valores jurídicos, as normas jurídicas limitativas de direitos com o valor eficiência que fundamente toda a ordem econômica.

\section{Referências}

BAUDIN, Louis. Estatização ou economia livre? A aurora de um novo liberalismo. São Paulo: Tangará, 1978.

GOM ES, Sergio Alves. Hermenêutica constitucional: um contributo à Constituição do Estado Democrático de Direito. Curitiba: Juruá, 2008.

HERITAGE FOUNDATION. Disponível em: http:// www.heritage.org Acesso em 30 mar. 2009.

KELSEN, Hans. Teoria pura do direito. 3. ed. São Paulo: RT, 2002.

RADBRUCH, Gustavo. Introdução à ciência do direito. São Paulo: Martins Fontes, 1999.

REALE, M iguel. A visão integral do direito em Kelsen, in. Estudos de filosofia do direito: Uma visão integral de Hans Kelsen. Coordenação Geral Luiz Regis Prado, Munir Karam. São Paulo: RT, 1984.

ROSSETTI, José Paschoal. Introdução à economia. 17.ed., São Paulo: Atlas, 1992.

SANDRONI, Paulo, Novíssimo dicionário de economia. 2. ed., São Paulo: Best Seller, 1999.

SANTIAGO, Luciano Sotero. Direito da concorrência: doutrina e jurisprudência. Salvador: JusPodivm, 2008.

VILANOVA, Lourival. Escritos jurídicos e filosóficos. Vol. 1. São Paulo: Axis M undi: IBET, 2003. 